\title{
ANÁLISE DO BALANCIM DA SUSPENSÃO DO PROTÓTIPO FÓRMULA SAE POR MÉTODO DE ELEMENTOS FINITOS
}

\author{
D. A. BARROSO ${ }^{2}$, J. A. BESSA', C. A. D. BEZERRA ${ }^{2}$, J. L. MORAES ${ }^{1}$ e A. R. ALEXANDRIA ${ }^{1}$ \\ ${ }^{1}$ Instituto Federal de Educação, Ciência e Tecnologia do Ceará - IFCE \\ ${ }^{2}$ Universidade Federal do Ceará - UFC \\ auzuir@gmail.com
}

Artigo submetido em junho/2014 e aceito em agosto/2015

DOI: $10.15628 /$ holos.2015.2189

\section{RESUMO}

Este trabalho tem como objetivo o estudo do balancim, um dispositivo da suspensão do veículo Fórmula SAE que recebe os esforços oriundos do movimento de rolagem do veículo e os transmite para a estrutura do chassi de uma forma minimizada por uma relação de momento e suavizada pelo conjunto mola - amortecedor. Realiza-se uma revisão sobre parâmetros usados em dinâmica veicular e uma análise geométrica das forças e dos esforços provocados por tais. Em seguida, faz-se a análise pelo método dos elementos finitos, que utiliza a teoria de discretização de sistemas e analisa a resistência do componente baseado na energia de distorção, determinando a tensão máxima sofrida pelo componente e a região de maior solicitação e o fator de segurança para um carregamento estático. A função principal do balancim, que é reduzir a força transmitida ao chassi devido ao movimento de rolagem e consequente solicitação da suspensão, é tida como satisfatória, uma vez que a força aplicada na roda e que seria transmitida ao chassi foi reduzida de $3833,9 \mathrm{~N}$ para $3496,48 \mathrm{~N}$ pelo mecanismo formado entre o balancim. A resistência do balancim aos esforços provocados pelas forças a ele impostas também foi atendida de forma satisfatória para o material selecionado à fabricação, uma vez que os cálculos dos Fatores de Segurança para carregamento estático comprovam tal afirmação.

PALAVRAS-CHAVE: Balancim, suspensão, método de elementos finitos.

\section{ANALYSIS OF THE SUSPENSION ROCKER OF FORMULA SAE PROTOTYPE BY FINITE ELEMENT METHOD}

\begin{abstract}
This work aims to study the rocker. This is a device of the suspension of Formula SAE vehicle that receives efforts from the motion scrolling of the vehicle and transmits them to the chassis frame minimized by a momentum ratio and smoothed by the set spring - damper. A review of parameters used in vehicle dynamics and a geometric analysis of the forces and stresses caused by such was carried out. Then, the analysis by the finite element method was applied. This analysis uses the theory of discretization of systems and examines the strength of the component based on the distortion energy, determining the maximum straining experienced by the
\end{abstract}

component and the region of higher demand. The main function of the rocker, which is to reduce the force transmitted to the chassis due to roll movement and consequent application of the suspension, is taken as satisfactory, since the force applied to the wheel and which would be transmitted to the chassis is reduced from $3833.9 \mathrm{~N}$ to $3496.48 \mathrm{~N}$ to the mechanism formed between the rocker. The rocker resistance to stresses caused by the forces imposed on him was also served to the satisfaction of the material selected to manufacture, since the calculation of security factors for static load prove such a claim.

KEYWORDS: Rocker, suspension, the finite element method. 


\section{INTRODUÇÃO}

Desde a criação do automóvel, a indústria automobilística concentra esforços para tornálo mais confortável e seguro (ALVES, 1997). Com o surgimento dos primeiros automóveis, os tipos de suspensão eram bastante triviais. A partir da evolução tecnológica, foram surgindo diversas geometrias e a engenharia foi desenvolvendo estudos sobre os mais variados tipos de suspensão. Hoje em dia existem vários tipos de suspensão aplicados para os mais variados veículos, porém, a grande dificuldade atual está em vincular o conforto com a segurança do usuário.

Para as mais variadas configurações de veículos tem-se um determinado tipo de suspensão adequado, como por exemplo, a suspensão adotada no protótipo Fórmula SAE UFC, consiste no tipo duplo braço em A. Esse tipo de suspensão não preza pelo conforto do usuário, dando prioridade à segurança do veículo, adotando ângulos e medidas que tornam o carro bastante estável nas curvas e nas situações de maior solicitação. O resultado dessa configuração é uma suspensão bastante dura, que faz com que o piloto sinta-se desconfortável, mas tenha um carro com o máximo de aderência e potência transmitida (PINTO, 2007).

A concorrência de mercado e as competições automobilísticas levaram engenheiros a desenvolver métodos de validação da dinâmica e do desempenho veicular, e um grande número de obras foram publicadas e hoje compõem uma vasta gama de conteúdo a respeito dos termos, componentes e sistemas de um automóvel, muito embora, as montadoras mantenham em sigilo seus métodos adotados no desenvolvimento de um projeto (MERLING, 2007).

O propósito desse trabalho é dimensionar e analisar o balancim da suspensão do protótipo Fórmula SAE UFC. Primeiramente, realiza-se uma revisão bibliográfica sobre projetos de suspensão automotiva, em especial o trabalho intitulado Projeto e desenvolvimento do sistema de Suspensão e Direção de um veículo Fórmula SAE, cujo, é tido como base para as informações relacionadas neste trabalho. Após isso, o método dos elementos finitos é colocado em questão. São abordadas as limitações referentes à forma, material e dimensões do balancim, bem como as forças a ele aplicadas durante o movimento de rolagem na situação crítica de frenagem conjugada a uma curva e representadas as medidas de largura de eixo e distância entre eles, que serão utilizadas nos cálculos posteriores. A seguir, são demostrados os valores referentes à magnitude das forças aplicadas no balancim para análise da sua resistência. E assim, apresentam-se análises realizadas por MEF (Método dos Elementos Finitos), relacionando as reações sofridas pelo balancim, demonstrando as regiões mais solicitadas da estrutura do componente da suspensão. Uma síntese a respeito da seleção do material e da geometria para a fabricação do balancim é realizada.

\section{UMA BREVE REVISÃO BIBLIOGRÁFICA}

\subsection{SUSPENSÃO FÓRMULA SAE}

Os grandes fabricantes de veículos na atualidade estão tendo grande preocupação com o problema do aumento da temperatura média do planeta. Dentro do que se pode ser feito para minimizar tal problema, engenheiros da mobilidade no mundo todo estão desenvolvendo motores com uma menor cilindrada e maior eficiência conjugada (REAA, 2008). 
O projeto Fórmula $\mathrm{SAE}$, por ser uma iniciativa da sociedade dos engenheiros da mobilidade (SAE Brasil), vincula bem esta preocupação atual com o regulamento da competição, assim, as equipes que visam um maior destaque, prezam por otimização nos mais variados sistemas que compõem o veículo, entre eles, a suspensão.

O sistema de suspensão dos automóveis tem sua origem nas carroças puxadas por animais. As carroças tinham suas rodas rígidas e sem movimento de translação em relação às carrocerias, e todas as cargas geradas pelo movimento de rolagem eram transmitidas diretamente do piso aos tripulantes. Depois das carroças surgiu uma suspensão que possuía rodas rígidas acopladas ao veículo pelo uso de um feixe de molas.

Pra este tipo de suspensão, os tripulantes ainda sentiam grande parte da excitação de base causada pelo terreno, sendo, portanto, de menor amplitude, quando comparado com o caso da inexistência do feixe de molas (MERLING, 2007). Com o desenvolvimento da engenharia automotiva, temos, hoje, diversos modelos e geometrias de suspensão, utilizadas nos mais variados modelos de veículos da atualidade, justificados pela contínua finalidade em se desenvolver modelos de suspensão que evitem ao máximo a transmissibilidade das irregularidades do piso ao veículo e aos ocupantes e em manter as rodas sempre em posição favorável nas curvas e em contato com o solo.

A suspensão de um Fórmula SAE é um sistema que costuma ser bastante otimizado, sendo fabricada pela maioria das equipes, de materiais leves e resistentes, capazes de suportar com segurança as solicitações proporcionadas pelo movimento do veículo. Dentre os componentes da suspensão, o balancim, cuja função é suavizar os esforços recebidos pelos pneus e que são transmitidos ao chassi, deve ser dimensionado para que se tenha um bom desempenho, de forma que não comprometa muito o conforto do piloto, se preocupando também com a quantidade de massa que será somada ao carro. A Figura 1 mostra o exemplo de um balancim na suspensão de um Fórmula SAE que possui apenas um conjunto mola - amortecedor na suspensão traseira.

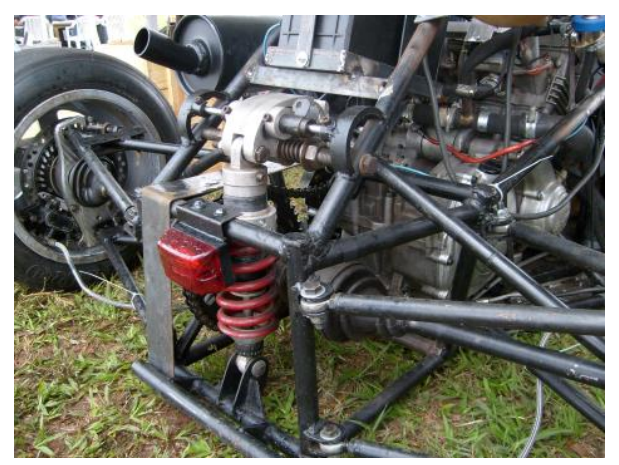

Figura 1 - Foto de tipo de balancim

\subsection{MÉTODO DE ELEMENTOS FINITOS (MEF)}

O sucesso na solução de um cálculo para determinada estrutura mecânica não está vinculado apenas ao domínio de um recurso matemático, mas à capacidade apresentada pelo engenheiro de entender a natureza física do problema que se propõe a resolver. A identificação dos pontos relevantes do problema em estudo permite estimar hipóteses sobre o comportamento do sistema estrutural a ser analisado, de forma a se obter um bom desenvolvimento do projeto em desenvolvimento. 
Ao iniciar um processo de cálculo da estrutura objeto de análise, o projetista deve formular um esquema de cálculo para essa estrutura, obtendo uma idealização de forma que se possa analisá-la (FILHO, 2000). A maior parte das estruturas usadas na prática são bastante complexas para serem analisadas pelo método analítico de solução matemática baseado no estudo das Equações Diferenciais, que descreve o equilíbrio das estruturas.

Para estruturas arbitrariamente definidas, a solução analítica muitas vezes torna-se impossível, e o problema exige grandes simplificações se quisermos aplicar as soluções prontas, resultando em cálculos pouco precisos (FILHO, 2000).

Os métodos analíticos conhecidos permitem o cálculo da resposta precisa dos deslocamentos, deformações e tensões em toda a estrutura, isto é, nos seus infinitos pontos, uma vez que a divisão se dá por elementos diferenciais, porém estas soluções são conhecidas apenas para alguns casos, diferenciados da maioria das aplicações práticas encontradas no cotidiano (FILHO, 2000).

Na década de 1950 engenheiros e pesquisadores envolvidos no desenvolvimento de aviões a jato na Boeing iniciaram os primeiros trabalhos práticos no estabelecimento do MEF (Método de Elementos Finitos) aplicados à indústria aeronáutica. M. J. Turner, R. W. Clough, H. C. Martin e L. J. Topp publicaram em 1956, um dos primeiros artigos que delinearam as principais idéias do MEF, entre elas a formulação matemática dos elementos e a montagem da matriz de elementos.

O Método dos Elementos Finitos tem como ideia central a subdivisão do domínio completo de um meio contínuo em elementos menores de geometrias simples, interligados entre si por pontos nodais que formam elementos e uma malha, denominada malha de elementos finitos, ou seja, faz-se a discretização do domínio objetivando facilitar a solução (AZEVEDO, 2003; SORIANO, 2003).

Segundo Zienkiewicz e Taylor (2000), a escolha do tipo de elemento e da função de forma são fatores que influenciam significativamente na convergência dos resultados e ficam a encargo do responsável pela analise, logo o usuário de programas deve ter domínio sobre o assunto.

Com esse procedimento, tem-se a oportunidade de estudar o comportamento dos elementos e depois sintetizar as soluções parciais para o estudo do sistema global. $\mathrm{Na}$ análise computacional utilizando o método dos elementos finitos é vinculada a ideia de um sistema contínuo discreto que possibilita uma solução aproximada, simulando a estrutura como uma montagem de elementos com comprimento finito, e não diferencial como no caso analítico. 0 sistema se subdivide em elementos de modo que a estrutura inteira é modelada por um agregado de estruturas simplificadas conectadas por pontos conhecidos como nós (FILHO, 2000).

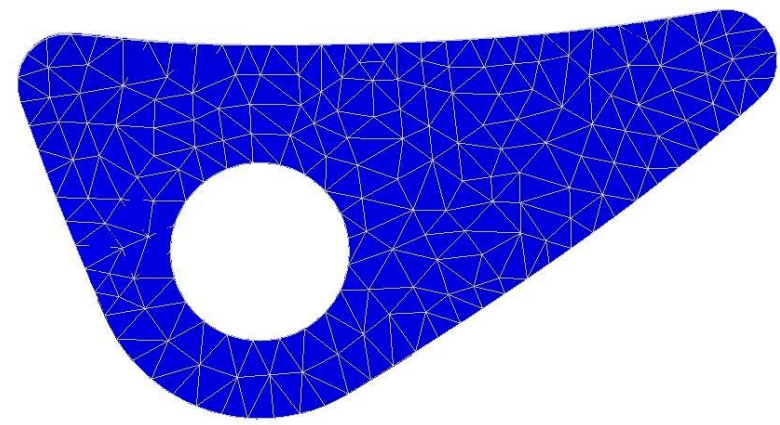

Figura 2 -Imagem do modelo inicial do balancim com a divisão finita dos elementos. 
A Figura 2 mostra uma malha triangular gerada no modelo inicial do balancim.

O número de pontos discretos na estrutura do sistema é escolhido de forma que seja o suficiente para representar o deslocamento do conjunto inteiro de forma aproximada. $\mathrm{O}$ modo como a estrutura se comporta entre os nós do modelo durante um carregamento dependerá das propriedades atribuídas ao elemento escolhido. Este elemento deve ser definido adequadamente com a situação física, tornando-a bem modelada para que sejam desnecessárias as decisões de engenharia durante o processo computacional (FERNANDES, 2002).

Durante a análise de um sistema aplica-se a ideia de um diagrama de corpo livre e assumese que, se a estrutura toda se encontra em estado de equilíbrio, então cada elemento discreto também está em equilíbrio, substituindo o elemento diferencial do modo analítico por um elemento finito. O complexo de elementos unidos pelos nós e em formato variável de acordo com a situação física do sistema é conhecido como malha de elementos finitos e seus elementos podem ser escolhidos em diferentes formas geométricas permissíveis de acordo com a abrangência do software utilizado no estudo.

\section{PROJETO E DIMENSIONAMENTO}

Para dimensionar o balancim foi estabelecida uma relação de momento com o intuito de promover a dispersão da energia que é acumulada devido à transferência de massa lateral e longitudinal durante uma situação crítica de rolagem. Essa relação foi escolhida como sendo de dois para um, ou seja, a distância entre o pino central e a fixação do conjunto mola - amortecedor deve ser duas vezes a distância deste mesmo pino à fixação do tirante da roda, conforme pode ser visto na Figura 3.

Partindo dessa relação inicial, e obtendo-se as solicitações decorrentes do movimento de rolagem do veículo será feito um estudo com o auxílio de um software para validar o uso deste componente da suspensão. As solicitações transmitidas à suspensão de um veículo podem ser devido a irregularidades na pista, bem como às transferências de peso lateral e longitudinal, conforme citado no segundo capítulo deste trabalho, porém, as irregularidades da pista serão desconsideradas, uma vez que a superfície do trajeto percorrido pelo veículo Fórmula SAE é selecionada para o mínimo de aceleração vertical da suspensão. Limitações pertinentes ao espaço interno necessário à fixação do balancim devem ser levadas em conta, assim como as limitações pertinentes aos custos do projeto.

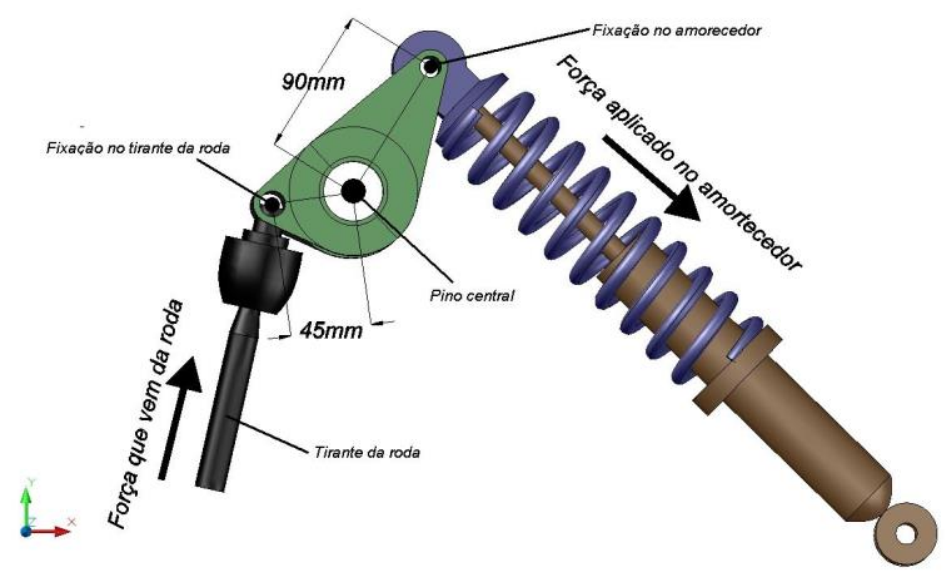

Figura 3 - Relação desejada na montagem do balancim. 


\subsection{ANTEPROJETO DO BALANCIM}

Partindo das limitações referentes ao espaço existente para a montagem da suspensão do protótipo foi elaborado um modelo inicial para o balancim, onde o mesmo pode ser visualizado na Figura 4.

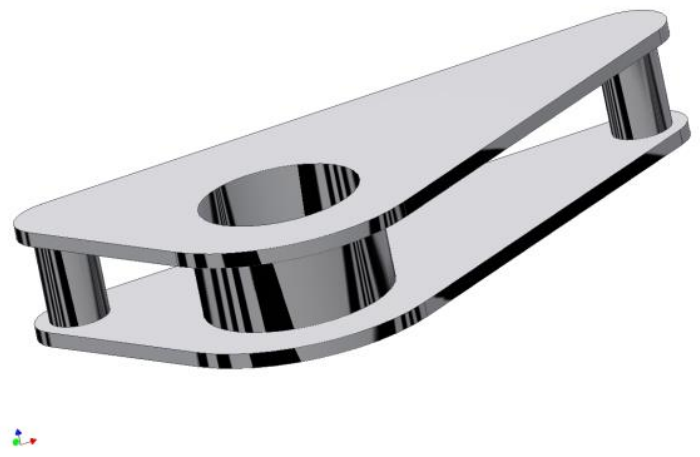

Figura 4 - Projeto do Balancim em três dimensões.

A seleção do material para a fabricação do balancim, assim como de todo o protótipo foi feita atentando-se principalmente para o custo de material e fabricação, pois o custo do projeto também é um quesito na somatória dos pontos para a classificação na competição. Atentando-se principalmente para o custo, o material escolhido para a fabricação do balancim foi o aço estrutural ABNT 1020, cujas propriedades de resistência correspondem bem às solicitações a ele impostas.

De acordo com essas propriedades e com o espaço disponível para alocar o balancim na suspensão do protótipo, foi elaborado um modelo inicial e fabricado utilizando-se uma chapa de aço carbono ABNT 1020 com três milímetros de espessura. A fixação do balancim no chassi se dá por meio de um pino central que funciona como eixo de giro, onde o mesmo é acoplado a um rolamento para permitir o movimento tangencial em relação ao plano composto pelo amortecedor, balancim, e o tirante da roda. A Figura 5 ilustra a fixação do balancim no chassi.

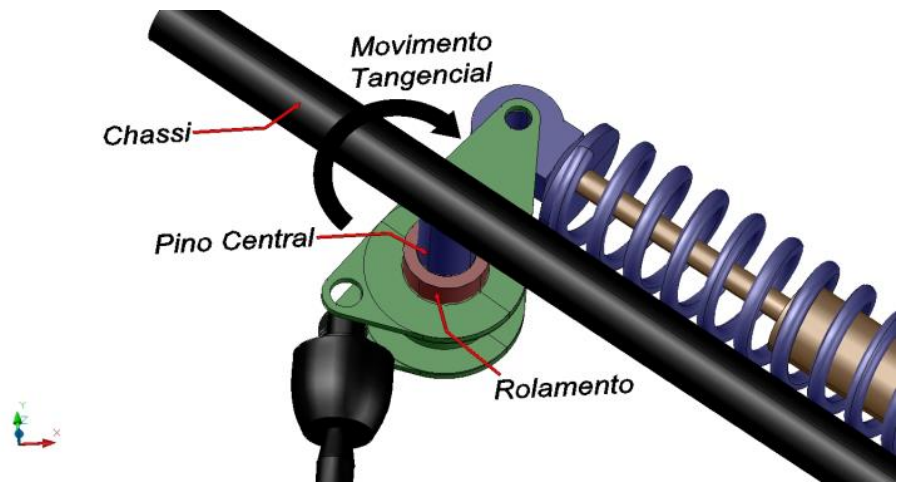

Figura 5 - Detalhe de fixação do balancim no chassi.

Como hipótese fundamental deste trabalho, será considerado que a força suportada pelo balancim possui o seu valor crítico quando o carro está em movimento realizando uma frenagem juntamente com uma curva, uma vez que a transferência de peso longitudinal devido a uma aceleração positiva (arranque) é menor do que na frenagem. O balancim foi projetado de modo que fosse intercambiável entre as quatro rodas do carro, ou seja, quaisquer das rodas pode receber o mesmo balancim, portanto, será realizado o estudo sobre a roda dianteira e externa a curva, uma vez que esta situação atende com segurança a todas as rodas. 


\section{PROJETO E DIMENSIONAMENTO}

Calculam-se as transferências de peso lateral e longitudinal que simulam o movimento de frenagem e curva. Após o cálculo dessas transferências, a solicitação a que é submetido o tirante da roda pode ser calculado através de um estudo da inclinação da força resultante, oriunda da massa que deverá ser suspensa pelo pneu externo da curva durante o movimento.

Para isso, deve-se considerar para efeito de simplificação, que o tirante da roda terá a mesma inclinação tanto quando estiver parado como em movimento na situação crítica considerada, uma vez que a inclinação varia tão pouco que será desconsiderada para que se possa obter o valor da força aplicada em função da posição inicial.

Após o cálculo da força que é aplicada no balancim pela fixação do mesmo no tirante, será calculado o momento resultante dessa força em relação ao pino central que fixa o balancim no chassi do protótipo e o momento resultante da força de reação do conjunto mola - amortecedor, obtendo-se dessa forma, a posição final do balancim após o carregamento. Com os valores da força do tirante e da posição final do balancim determina-se o valor da força de reação e em seguida realiza-se a análise para a validação da resistência do balancim, que será demonstrada na próxima seção.

\subsection{PARÂMETROS DE ENTRADA}

Para a aplicação das equações citadas anteriormente, torna-se necessário o conhecimento de todos os valores de entrada. A Tabela 1 lista todos os valores de entrada relevantes, dentre os parâmetros limitados pelo regulamento Fórmula SAE e as dimensões reais do protótipo, para os cálculos de forças e componentes para futuras análises.

Tabela 1- Parâmetros de entrada para o cálculo dos esforços. Fonte: Projeto e desenvolvimento do sistema de suspensão e direção de um veículo Fórmula SAE.

\begin{tabular}{|c|c|c|}
\hline Descrição do parâmetro & Valor & Simbologia \\
\hline Massa total $(\mathrm{kg})$ & 350 & $m$ \\
\hline Fração de massa na frente $(\%)$ & 40 & $m_{P}$ \\
\hline Altura do Centro de Gravidade $(\mathrm{mm})$ & 350 & $h_{C G}$ \\
\hline Distância entre eixos $(\mathrm{mm})$ & 1755 & $e e$ \\
\hline Bitola dianteira $(\mathrm{mm})$ & 1350 & $t$ \\
\hline Desaceleração máxima $\left(\mathrm{m} / \mathrm{s}^{2}\right)$ & 9,81 & $a$ \\
\hline Aceleração centrípeta $\left(\mathrm{m} / \mathrm{s}^{2}\right)$ & 16,667 & $a_{c}$ \\
\hline Constante de deformação $(\mathrm{N} / \mathrm{mm})$ & 23,51 & $K$ \\
\hline
\end{tabular}

\section{ANÁLISE COMPUTACIONAL}

A validação do desempenho do balancim será realizada por meio do método dos elementos finitos (MEF), simulando as cargas provenientes da massa inicial do veículo juntamente com as solicitações devido ao movimento de frenagem e curva, analisando a distribuição de tensões no componente da suspensão, localizando assim, os pontos de tensão máxima e mínima, calculando o fator de segurança para o carregamento estático, e analisando os deslocamentos, de acordo com os gráficos gerados pelo software utilizado. A Tabela 2 lista as forças e suas componentes no momento do equilíbrio entre os momentos, calculadas anteriormente para aplicação na aplicação computacional. 
Tabela 2 - Relação da magnitude das forças e componentes para análise.

\begin{tabular}{|c|c|}
\hline Força & Magnitude (N) \\
\hline$F_{B}$ & 3833,9 \\
\hline$F_{B x}$ & 0 \\
\hline$F_{B y}$ & 3833,9 \\
\hline$F_{A}$ & 3496,48 \\
\hline$F_{A x}$ & 2952,17 \\
\hline$F_{A y}$ & 1873,5 \\
\hline
\end{tabular}

\subsection{DISCRETIZAÇÃO DO MODELO}

A análise foi feita utilizando o elemento finito na forma triangular, o que resulta em uma malha triangular unida por nós que terão sua quantidade definida a seguir. A forma triangular do elemento finito, para o caso deste trabalho, se torna viável, uma vez que não viola o critério do escoamento do material para a aproximação linear do campo de tensões (SODRÉ, 2007).

\subsection{CONSIDERAÇÕES REFERENTES À APLICAÇÃO DOS CARREGAMENTOS}

A fixação do balancim no tirante da roda e no conjunto mola - amortecedor se dá por meio de parafusos. Considerando que os parafusos resistirão ao carregamento aplicado e transmitirão totalmente a carga para o corpo do balancim, o modelo gerado para a análise terá os parafusos substituídos por pinos que farão parte de uma estrutura homogênea e única.

\subsection{RESTRIÇÃO DE MOVIMENTO}

Para a simulação do carregamento sofrido pelo balancim, será restringido o movimento axial e radial do mesmo e, uma vez que as forças atuantes alcançarem o equilíbrio, será considerado que o movimento tangencial também será restrito e as forças atuantes serão aplicadas no balancim para a análise estática.

\subsection{DADOS DE ENTRADA}

Ao atingir o equilíbrio entre os momentos, o balancim terá sua posição final definida e as componentes encontradas serão os dados de entrada, juntamente com as devidas restrições consideradas no item anterior e a definição do material empregado na fabricação da peça.

\subsection{DESCRIÇÃO DO PROCEDIMENTO DE SIMULAÇÃO}

O primeiro passo para realizar a simulação é definir o modelo a ser analisado. Após isso, é definida a malha de acordo com as opções de geometria da mesma, nesse caso triangular.

A seguir definem-se as restrições de movimento, as solicitações, conforme a Tabela 3, e o material que será utilizado na fabricação. O número de nós é definido em função do pico de tensão obtido durante a análise. Para essa definição é utilizado um método conhecido como refinamento da malha, que consiste no seguinte procedimento:

É definido um número inicial de nós e aplicado o carregamento com as devidas restrições de movimento. Em seguida, aumenta-se o número de nós e aplica-se novamente o carregamento, com o objetivo de se comparar com o resultado anterior. No momento em que o valor da tensão 
máxima equivalente começar a decair, é definido o número de nós, e consequentemente, o número de elementos, concretizando-se o resultado final da simulação. Um gráfico de cores mostrando os pontos de tensão máxima e mínima equivalente é gerado, em função da discretização do modelo, bem como um gráfico com a representação do fator de segurança e do deslocamento sofrido pelo balancim.

\subsection{AVALIAÇÃO DOS RESULTADOS}

Definidos os gráficos, é possível avaliar a resistência da peça com relação ao material empregado na fabricação e ao modelo inicial definido para o projeto. Os gráficos são gerados a partir do critério de Von Misses (DA CRUZ, 2006) que se baseia na concepção da energia de distorção, ou seja, a energia relacionada à mudança na forma do material. A tensão de Von Misses incorpora todas as componentes de tensão normal e cisalhante.

A segurança do sistema analisado tem sua confirmação na situação em que o valor máximo da energia de distorção a que é submetido, por unidade de volume, estiver abaixo do limite de escoamento do material, ou seja, da energia de distorção necessária para provocar o escoamento do material. A determinação do limite de escoamento do material é obtida através de um ensaio de tração para um corpo de prova padronizado e seu valor pode ser encontrado em literatura específica para diversos materiais utilizados em processos de fabricação.

O fator de segurança para o sistema analisado, de acordo com o material utilizado na fabricação, pode ser demonstrado pela seguinte equação:

$$
F S=\frac{S_{y}}{\sigma_{\max }^{\prime}}
$$

onde $S_{y}$ é o limite de resistência ao escoamento para o aço estrutural ABNT 1020, dado em MPa, e $\sigma_{\text {max }}^{\prime}$ é a tensão de Von Misses calculada a partir da análise representada pelo software, dada em MPa. Para um fator de segurança inferior ou igual a unidade, o componente ou sistema analisado não irá resistir ao carregamento e tenderá a escoar em virtude do valor da tensão equivalente aplicada ser maior do que o limite de escoamento.

\subsection{SIMULAÇÃO}

Após repetidas simulações, refinando a malha para obter o pico de tensão, determinou-se uma malha com 4651 nós, formando 2123 elementos, e considerando o balancim como uma estrutura homogênea, de material isotrópico, com as propriedades independentes da temperatura, e considerando o deslocamento linear, ou seja, a tensão diretamente proporcional ao deslocamento, obteve-se o seguinte resultado para o carregamento obtido anteriormente.

Tabela 3 - Resultado da simulação do carregamento no balancim para o aço estrutural SAE1020.

\begin{tabular}{|l|l|l|}
\hline \multicolumn{1}{|c|}{ Nome } & Valor mínimo & Valor máximo \\
\hline Tensão Equivalente (Von Misses) & $0 \mathrm{Mpa}$ & $81,62 \mathrm{MPa}$ \\
\hline Deslocamento & $0 \mathrm{~mm}$ & $0,06312 \mathrm{~mm}$ \\
\hline Fator de Segurança & 4,815 & - \\
\hline
\end{tabular}


A partir da equação 1 do fator de segurança pode-se calcular o valor demonstrado na Tabela acima como:

$$
F S=\frac{393 M P a}{81,62 M P a}=4,815
$$

Para $F S=4,815$, pode-se concluir que o balancim irá resistir ao carregamento de forma satisfatória, uma vez que a energia de distorção máxima aplicada não ultrapassou o limite de escoamento do material. Os gráficos gerados pelo software para representar as regiões de maior solicitação do balancim em função da distribuição de cores são mostrados nas Figuras 6, 7 e 8.

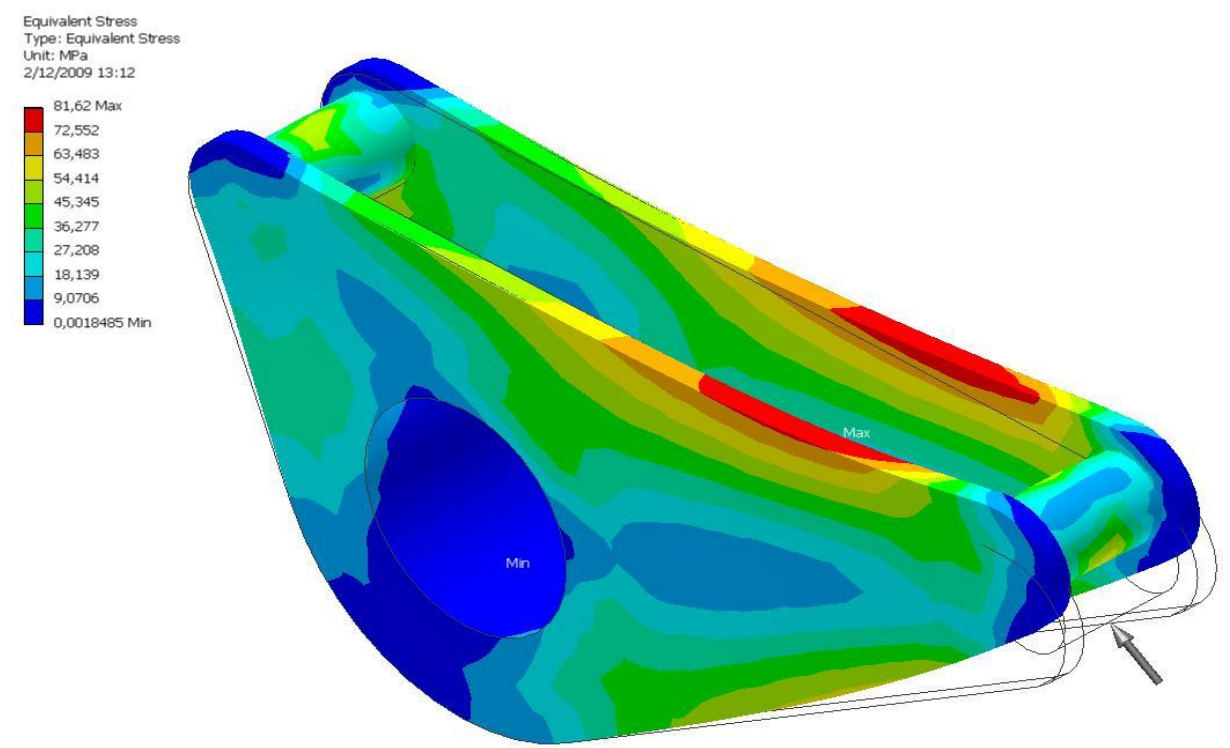

Figura 6 - Gráfico de cores para a tensão de Von Misses.

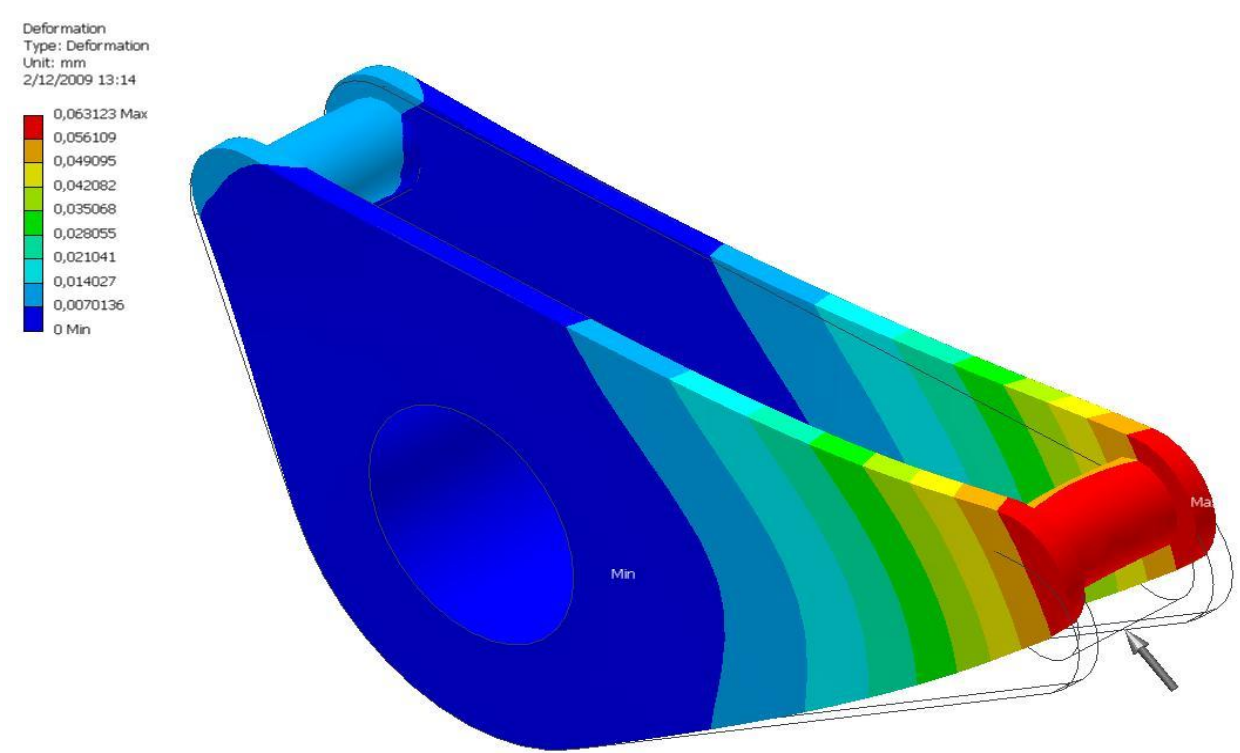

Figura 7 - Gráfico de cores para o deslocamento sofrido pelo balancim. 


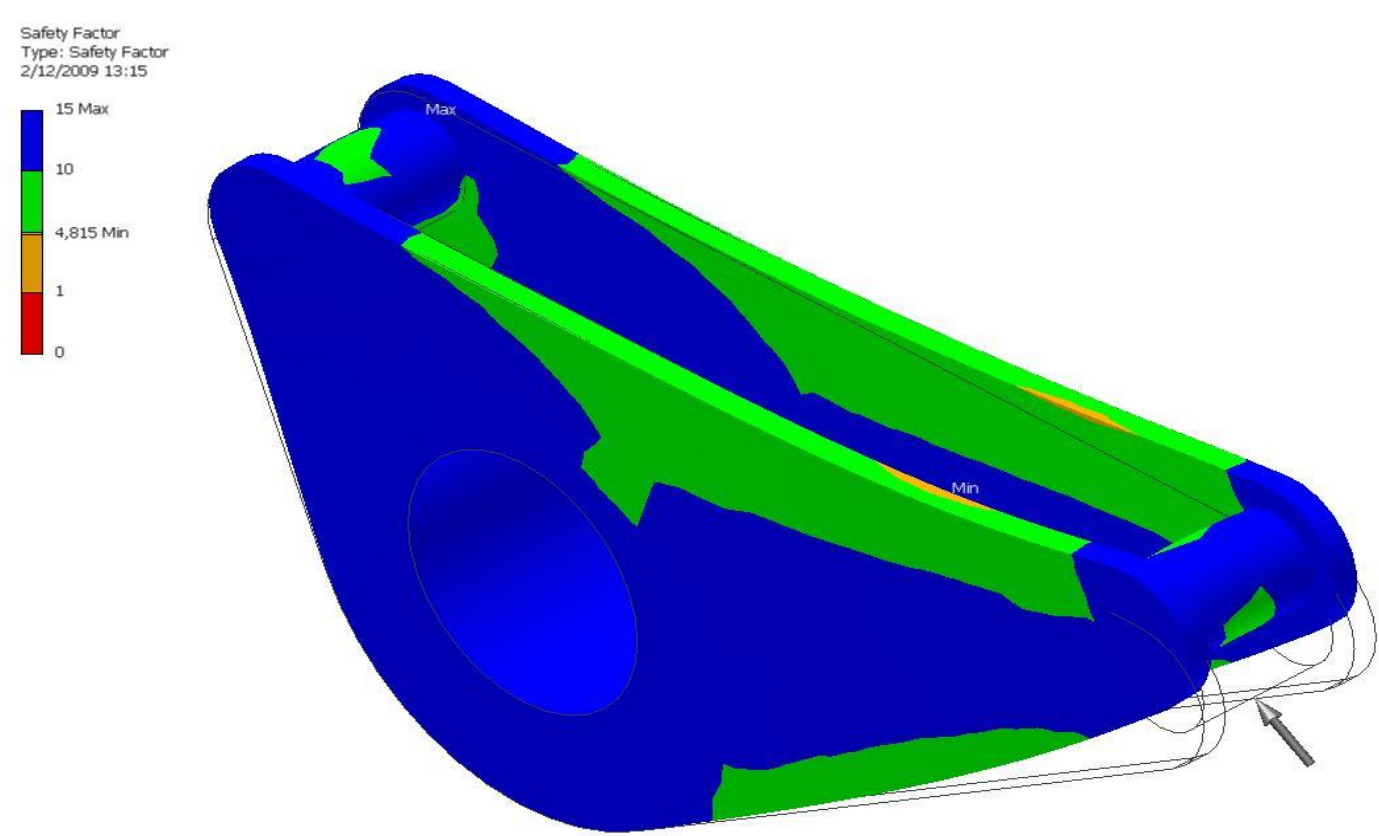

Figura 8 - Gráfico de cores para o fator de segurança do balancim.

\section{CONSIDERAÇÕES FINAIS}

A função principal do balancim, que é reduzir a força transmitida ao chassi devido ao movimento de rolagem e consequente solicitação da suspensão, é tida como satisfatória, uma vez que a força aplicada na roda e que seria transmitida ao chassi foi reduzida de $3833,9 \mathrm{~N}$ para $3496,48 \mathrm{~N}$ pelo mecanismo formado entre o balancim, o tirante da roda e o conjunto mola amortecedor.

A resistência do balancim aos esforços provocados pelas forças a ele impostas também foi atendida de forma satisfatória para o material selecionado à fabricação, uma vez que os cálculos dos Fatores de Segurança para carregamento estático comprovam tal afirmação.

A partir destes valores pode-se aprofundar simulações mais detalhadas usando o Método dos Elementos Finitos visando a redução de massa ou até mesmo a viabilidade de fabricação do balancim em alumínio.

\section{AGRADECIMENTOS}

Agradecemos ao Instituto Federal de Educação, Ciência e Tecnologia do Ceará e à Universidade Federal do Ceará pela infraestrutura necessária ao trabalho.

\section{REFERÊNCIAS BIBLIOGRÁFICAS}

1. ALVES, P. S. L. Análise Comparativa do Desempenho de uma Suspensão Veicular Considerando Elementos Passivos e Ativos. 1997. 131 f. Dissertação (Mestrado em Engenharia Mecânica) Universidade Estadual de Campinas, Campinas, 1997.

2. AZEVEDO, Alvaro Ferreira Marques. Método dos Elementos Finitos. 10 Edição, Portugal: Faculdade de Engenharia da Universidade do Porto, 2003. 
3. DA CRUZ, M. D. Autodesk Inventor 10: Teoria e Prática. Versões Series e Professional. São Paulo: Editora Érica, 2006.

4. FERNANDES, J. L. C. Aplicação dos Elementos Finitos Singulares Híbridos na Mecânica da Fratura Linear Estática Bidimensional. 2002. 89 f. Tese (Mestrado em Engenharia Aeronáutica e Mecânica) - Instituto Tecnológico de Aeronáutica, São José dos Campos, 2002.

5. FILHO, A. A. Elementos Finitos: A Base da Tecnologia CAE. 2.ed. São Paulo: Editora Érica, 2000.

6. MERLING, M. C. C. Uma Abordagem Gerencial para o procedimento de Projeto de Suspensões de Veículos Terrestres. 2007. 173f. Dissertação (Mestrado em Engenharia Mecânica) Pontifícia Universidade Católica do Rio de Janeiro, Rio de Janeiro, 2007.

7. MILLIKEN, William F.; MILLIKEN, Douglas L. Race Car Vehicle Dynamics; SAE International Editions, 1995.

8. NORTON, R. L. Projeto de Máquinas. 2.ed. Worcester: Bookman, 2006.

9. PINTO, T. H. A. Projeto e Desenvolvimento do Sistema de Suspensão e Direção de um Veículo Fórmula SAE. 2007. 78 f. Monografia (Graduação em Engenharia Mecânica) - Centro de Tecnologia, Universidade Federal do Ceará, Fortaleza, 2007.

10. REVISTA ENGENHARIA AUtOMOtIVA E AEROESPACIAL. São Paulo: SAE Brasil, 2001 - . Trimestral.

11. SAE INTERNATIONAL. Fórmula SAE Brasil. Rules For 2007 Formula SAE Event. São Paulo: SAE International Editions, 2007.

12. SODRÉ, D. J. R. Análise Plástica Limite por Elementos Finitos e Programação Matemática. 2007. 211 f. Tese (Doutorado em Engenharia Aeronáutica e Mecânica) - Instituto Tecnológico de Aeronáutica, São José dos Campos, 2007.

13. SORIANO, Humberto Lima. Método dos elementos finitos em análise de estruturas. São Paulo: EDUSP, 2003

14. ZIENKIEWICZ, Olgierd Cecil ; TAYLOR, R. L. The finite element method, vol. 01: The Basis. 5o edição. Butterworth-Heinemann Linacre House, 2000. 